\title{
MANAJEMEN PELATIHAN PENGANTAR KERJA DI PUSDIKLAT PEGAWAI KEMENTERIAN KETENAGAKERJAAN (JAKARTA, 2017)
}

\author{
Rora Irna Hasanah, Dr. Matin, M.Pd, Amril Muhammad, SE, M.Pd
}

\section{rorairna@gmail.com}

\begin{abstract}
This study aims to determine the introductory training management at Ministry of Manpower Training and Education Center. In research on training management training focused on the planning and implementation of training. This research is a qualitative descriptive study. Determining the subject of this study using snowball sampling. Data collection techniques used were interviews, observation and documentation. Data were analyzed by descriptive qualitative.The results of the study indicate that the introductory training management Employees working in the Ministry of Employment Training Center include: 1) Planning training in with AKD (Training Needs Analysis) tailored to the needs on the ground. Formulate the curriculum, syllabus, teaching materials, methods, schedules, and lecturer. After conducting a needs analysis phase, 2) The training begins with a letter calling the membership then process the results of field organizers formulation of curriculum, syllabus and schedule to be processed into a tentative schedule. Next is a learning process begins with classical training and learning outside the classroom there are street vendors (Practice Field work) in order to train the participants in terms of skills. After the stage of the learning process of the next stage is the end of the training seminar is the last stage of determining graduation training participants were announced at the closing. Then follow-up after the participants follow the training is coaching and empowerment of the participants returned to the horse's mouth each work unit. Employee Training Center and related Technical Unit should prepare earlier and more intensively communicate in detail in preparing the training. the need for alternative plans or concepts implementation and submitted directly to the relevant parties prior to the implementation of the training in order to anticipate a technical error or adjustment situation and conditions on the ground so it does not need to re-coordination.
\end{abstract}

Keywords: Training, Training Planning, Implementation Training

\section{Pendahuluan}

Sumberdaya manusia (SDM) merupakan salah satu faktor kunci dalam menciptakan SDM yang berkualitas agar mampu berdaya saing dalam kancah global yang selama ini kita abaikan. Globalisasi yang sudah pasti dihadapi oleh bangsa Indonesia menuntut adanya efisiensi dan daya saing dalam dunia usaha.

Salah satu upaya untuk meningkatkan kualitas sumber daya manusia adalah melalui pendidikan, baik pendidikan formal maupun pendidikan informal. Sumber Daya Manusia dalam suatu perusahaan merupakan aset penting bagi perkembangan perusahaan. Di dalam dunia kerja, telinga kita akrab dengan istilah pelatihan kerja atau training atau pelatihan. Maka dari itu untuk meningkatkan keterampilan dan kualitas kerja para karyawan, banyak perusahaan mengadakan training atau pelatihan kerja. 
Pendidikan dan Pelatihan (Diklat) merupakan salah satu kegiatan yang dilakukan suatu lembaga atau organisasi dalam rangka mengembangkan kualitas Sumber Daya Manusia. Diklat diperlukan agar para tenaga kerja dapat mengembangkan tugas kewajiban serta tanggung jawab pekerjaan di tempat kerja. Setelah diadakan Diklat sesorang diharapkan dapat menjadi lebih baik dalam bekerja dan mampu mengembangkan berbagai ilmu dan keterampilan yang telah didapat selama Diklat.

Kementerian Tenaga Kerja sebagai bagian dari sistem pemerintahan mempunyai misi yang penting dalam menjalankan amanat Undang-Undang Dasar (UUD) 1945 pasal 27 ayat (2), ayat tersebut menyatakan bahwa, tiaptiap warga berhak atas pekerjaan dan penghidupan yang layak bagi kemanusiaan. Dalam rangka mengatasi permasalahan ketenagakerjaan yang semakin kompleks tersebut, Kementrian Ketenagakerjaan mengupayakan strategi yang bersifat penyelamatan, rehabilitasi dan pengembangan. Strategi yang bersifat penyelamatan, antara lain diarahkan untuk menciptakan dan perluasan lapangan kerja.

Menurut informasi yang diperoleh peneliti dari hasil observasi lapangan, Pusdiklat Pegawai Kementerian Ketenagakerjaan sebagai lembaga pendidikan dan pelatihan pemerintah, berkewajiban untuk menyelenggarakan Diklat Aparatur bidang ketenagakerjaan. Dengan visi mewujudkan Pusdiklat Pegawai sebagai "Center of Excellent, Center of Development, Center of Empowerment (CEDE)" di bidang Pendidikan dan Pelatihan Pegawai dalam rangka mendukung Kebijakan dan Program Ketenagakerjaan. Hal ini dilakukan dengan misi, meningkatkan kualitas dan produktivitas PNS dibidang ketenagakerjaan, meningkatkan koordinasi dan fasilitasi penyelenggaraan

Sebagai bentuk konsekuensi penyeimbangan kualitas manajemen, Pusdiklat Pegawai Kementrian Ketenagakerjaan telah memperoleh sertifikat Sistem Manajemen Mutu ISO 9001: 2008. Pusdiklat Pegawai Kementrian Ketenagakerjaan juga telah memperoleh akreditasi sebagai Lembaga Diklat Kepemimpinan Tingkat III dan IV serta Diklat Prajabatan Golongan III, II, dan I dari Lembaga Administrasi Negara.

Dengan demikian tampak bahwa tugas dan fungsi diklat pengantar kerja sesuai dengan standar mutu yang digunakan. Untuk melakukan pelatihan yang maksimal perlu koordinasi yang lebih intens antar bidang kerja dan persiapan yang optimal untuk memaksimalkan proses pembelajaran yang lebih baik dan manfaat pelatihan dapat dirasakan oleh peserta pelatihan.

Berdasarkan latar belakang tersebut diatas maka penulis tertarik melakukan penelitian mengenai "Manajemen Pelatihan Pengantar Kerja di Pusdiklat Pegawai Kementerian Ketenagakerjaan". Dengan subfokus yang meliputi perencanaan pelatihan dan pelaksanaan pelatihan.

\section{Tinjauan Pustaka}

Manajemen merupakan sarana untuk mencapai suatu tujuan yang telah ditetapkan melalui peran orang lain. Menurut Parker management is the art of getting things done through people. Artinya, manajemen adalah seni melaksanakan pekerjaan melalui orangorang. Sedangkan definisi manajemen menurut Koontz dan O'Donnel"management is the creation and maintenance of an internal environment in an enterprise where individuals, working in groups, can perform efficiently and effectively towards the attainment of group goals". Artinya, 
manajemen adalah penciptaan dan pemeliharaan lingkungan internal perusahaan dimana individu, bekerja dalam kelompok, dapat melakukan efisiensi dan efektifitas menuju pencapaian tujuan kelompok. Manajemen merupakan kegiatan yang memilki susunan sistematis untuk mencapai sebuah tujuan. Sebagaimana definisi yang dikemukakan oleh Terry, "management is a distinct process consisting of planning, organizing, actuating and controlling performed to determine and accomplish the objectives by the use of people and resources". Artinya, manajemen adalah proses yang berbeda yang terdiri dari perencanaan, pengorganisasian, pelaksanaan dan pengendalian yang dilakukan untuk menentukan dan mencapai tujuan dengan menggunakan orang-orang dan sumber daya. Dari pendapat para ahli di atas maka, dapat disintesakan bahwa manajemen pada dasarnya merupakan seni atau proses dalam menyelesaikan sesuatu yang terkait dengan pencapaian tujuan. Dalam penyelesaian akan sesuatu tersebut, terdapat tiga faktor yang terlibat: Adanya penggunaan sumber daya organisasi, adanya proses yang bertahap dari mulai perencanaan, pengorganisasian, pengarahan dan pengimplementasian, hingga pengendalian dan pengawasan.

Kata pelatihan menurut Poerwadarminta berasal dari kata "latih" ditambah dengan awalan ke-, pe, dan akhiran -an yang artinya telah biasa, keadaan telah biasa diperoleh seseorang setelah melalui proses belajar atau diajar. Dapat disimpulkan pelatihan adalah proses belajar untuk membiasakan seseorang sesuai dengan tujuan pelatihan itu sendiri. Dalam istilah lain, Kenny menyebutkan yang dikutip oleh Basri dan Rusdiana, "training as satisfactorily the work required of him in his present job". Dapat disimpulkan bahwa pelatihan sebagai nilai pemuasaan pekerjaan yang dilakukan sekarang. Pelatihan memberikan pengalaman untuk memenuhi minat pekerjaan yang memberikan rasa puas. Sedangkan menurut Barbazette yang dikutip oleh Donni menyatakan bahwa, pada umumnya fungsi pelatihan dalam organisasi adalah untuk mengembangkan pengetahuan dan keterampilan serta membentuk sikap yang akan memenuhi kebutuhan bisnis organisasi. Pelatihan mempersiapkan para pegawainya agar terampil dalam aspek kognitif dan efektif sesuai kebutuhan organisasi. Senada yang dikatakan oleh Flippo definisi pelatihan, training is the act of increasing the knowledge and skill of an employee for doing a particular job. Artinya, pelatihan adalah tindakan meningkatkan pengetahuan dan keterampilan karyawan untuk melakukan pekerjaan tertentu.

Menurut Robbins dan Coulter yang dikutip oleh Ernie dan Kurniawan, planning is a process that involves defining the organization's goals, establishing an overall strategy for achieving those goals, and developing a comprehensive set of plans to integrate and coordinate organizational work. Artinya, perencanaan adalah sebuah proses yang dimulai dari penetapan tujuan organisasi, menentukan strategi untuk pencapaian tujuan organisasi tersebut secara menyeluruh, serta merumuskan sistem perencanaan yang menyeluruh untuk mengintegrasikan dan mengoordinasikan. Menurut Goetz yang dikutip oleh Hasibuan, "planning is the fundamentally choosing and a planning problem arises only when alternative course of action is discovered". Artinya, perencanaan adalah pemilihan yang fundamental dan masalah perencanaan timbul, jika terdapat alternatif-alternatif. Jadi, perencanaan adalah pekerjaan mental untuk memilih sasaran, kebijakan, prosedur, dan program yang diperlukan untuk mencapai apa yang diinginkan pada masa yang akan datang. 
Senada dengan yang dikemukakan oleh Hasibuan, perencanaan adalah sejumlah keputusan mengenai keinginan dan berisi pedoman pelaksanaan untuk mencapai tujuan yang diinginkan itu. Jadi, setiap rencana mengandung dua unsur yaitu tujuan dan pedoman.

$\quad$ Menurut
Implementation Research Network
pelaksanaan adalah, "implementation is
defined as a specified set of activities
designed to put into practice an activity or program of known dimensions". Artinya, pelaksanaan didefinisikan sebagai suatu set tertentu dari kegiatan yang dirancang untuk dimasukkan ke dalam praktik kegiatan atau program yang dikenal dari dimensinya. Sedangkan Shaw mendefinisikan pelaksanaan yaitu, "the purpose of the implementation phase is to implement the training plan that you designed and developed in earlier phase of the systematic approach to training. This is when the learners undertake the activities of learning, produce the various tangible results that can be referenced as means to evaluate learners progress toward achieving the learning objectives, and evaluation occurs not only of the results produced by learners but also the activities of implementation to ensure those activities themselves are high-quality". Artinya, tujuan dari tahap implementasi adalah untuk melaksanakan rencana pelatihan yang telah dirancang dan dikembangkan di fase awal untuk pendekatan sistematis pelatihan. Implementasi adalah ketika peserta didik melakukan kegiatan belajar, menghasilkan berbagai hasil nyata yang dapat dirujuk sebagai sarana untuk mengevaluasi kemajuan peserta didik untuk mencapai tujuan pembelajaran, dan evaluasi terjadi tidak hanya dari hasil yang dihasilkan oleh peserta didik tetapi juga kegiatan pelaksanaan untuk memastikan kegiatan tersebut sendiri berkualitas tinggi.

\section{Metode Penelitian}

Penelitian ini menggunakan pendekatan kualitatuf dengan metode deskriptif analitik. Penelitian ini dilakukan di Pusdiklat Pegawai Kementerian Ketenagakerjaan yang terletak di Jl. Pusdiklat Depnaker, Kp. Lembur Kel/Kec Makassar, Jakarta Timur. Penelitian dilaksanakan selama kurang lebih lima bulan. Tahapan penelitian yang dilakukan terdiri dari tahap pra lapangan, tahap pekerjaan lapangan, dan analisis data. Tahap pra lapangan meliputi penyusunan rancangan penelitian, memilih lapangan penelitian, mengurus izin penelitian, menjajaki dan menilai keadaan di lapangan, memilih dan memanfaatkan informan, menyiapkan perlengkapan peneltian, tahap pekerjaan lapangan meliputi memahami latar penelitian dan persiapan diri, memulai kunjungan ke lapangan, dan berperan serta mengumpulkan data. Tahap analisis data terdiri dari proses reduksi data, penyajian data, dan verifikasi data.

\section{Hasil dan Pembahasan}

Pusdikat Pegawai merupakan Unit Eselon II, yang selalu muncul keberadaannya di lingkungan Lembaga Pemerintahan yang menangani tugas pendidikan dan pelatihan Pegawai Negeri Sipil. Sejalan dengan adanya perubahan kelembagaan di Indonesia, maka Lembaga yang menangani tugas Pendidikan dan Pelatihan Bidang Ketenagakerjaan dan Ketransmigrasian selalu mengalami perubahan. Pusdiklat Pegawai mempunyai tugas melaksanakan pendidikan dan pelatihan pegawai di bidang ketenagakerjaan berdasarkan kebijakan yang ditetapkan oleh menteri dan peraturan perundangundangan yang berlaku.

$$
\text { Jabatan Fungsional Pengantar }
$$

Kerja adalah jabatan yang
mempunyai ruang lingkup, tugas, 
tanggung jawab, wewenang, dan hak untuk melakukan kegiatan pelayanan antar kerja. Jabatan Fungsional Pengantar Kerja termasuk dalam rumpun ilmu sosial dan yang berkaitan. Instansi Pembina Jabatan Fungsional Pengantar Kerja yaitu KementerianKetenagakerjaan.

Proses perencanaan Diklat Pengantar Kerja mulai dari penentuan kurikulum, materi, seleksi peserta, hingga pengajar dilakukan oleh Pusdiklat Pegawai Kementerian Ketenagakerjaan bekerjasama dengan Unit Teknis terkait yaitu Direktorat Jendral Pembinaan Penempatan Tenaga Kerja dan Perluasan Kesempatan Kerja dan Biro Organisasi dan Kepegawaian.

Tahapan perencanaan Diklat Pengantar Kerja diawali dengan AKD (Analisis Kebutuhan Diklat) pengantar kerja dengan Unit Teknis terkait yaitu Biro Organisasi dan Kepegawaian dan Direktorat Pembinaan dan Penempatan Tenaga Kerja untuk menentukan kebutuhan dan jumlah angkatan diklat guna menghasilkan program-program diklat yang sesuai dengan kualifikasi tuntutan tugas dan perkembangan organisasi, pengetahuan, dan teknologi. Cara mengidentifikasi kebutuhan diklat pengantar kerja adalah dengan melihat kebutuhan pasar dari peraturanperaturan yang sudah ada dan melihat kebutuhan setiap daerah yang berbedabeda. Setelah melakukan tahap analisis kebutuhan, Pusdiklat melakukan tahap perencanaan dari segi program dan penyeleksian peserta. Pusdiklat bersama Dirjend Binapentaker, para ahli di bidang ketenagakerjaan dan Widyaiswara mengadakan rapat untuk pembahasan kurikulum yang akan digunakan. Selain itu, dilakukan pula peninjauan ulang kurikulum apakah masih relevan atau perlu direvisi untuk output peserta yang lebih baik. Di dalam rapat kurikulum dibahas mengenai materi, silabus, modul, serta
Widyaiswara yang akan mengisi materi Diklat Pengantar Kerja.

Menurut Bateman dan Snell, "need assessement is an analysis identifying the jobs, people, and departments for which training is necessary. Artinya, penilaian kebutuhan adalah analisis untuk mengidentifikasi pekerjaan, orang, dan departemen yang mana untuk kebutuhan pelatihan. Dalam rapat perumusan ditentukan terlebih dahulu tujuan yang akan dicapai dalam pelatihan yang akan dilaksanakan dengan menganalisis kebutuhan pasar. Analisis kebutuhan pelatihan di Bidang Program dan Evaluasi dilakukan oleh sub bidang Program. Hal-hal yang dianalisis adalah jumlah kebutuhan peserta diklat pengantar kerja, kebutuhan pasar sesuai dengan peraturan yang ada, kurikulum dan materi apakah masih relevan dengan kondisi terkini. Selanjutnya bidang program bersama Direktorat Jendral Pembinaan Penempatan Tenaga Kerja dan Perluasan Kesempatan Kerja, dan Biro Organisasi dan Kepegawaian merumuskan kurikulum, silabus, modul, metode, widyaiswara, jadwal diklat, menetapkan seleksi peserta. Setelah itu ditentukan perumusan program yang akan dijalankan. Hal ini sejalan dengan teori yang dikemukakan oleh Handoko yang menyatakan bahwa perencanaan meliputi, (1) Pemilihan atau penetapan tujuan-tujuan organisasi, (2) penentuan strategi, kebijakan, proyek, program, prosedur, metode, system, anggaran, dan standar yang dibutuhkan untuk mencapai tujuan.

Tahap pelaksanaan awal diklat pengantar adalah tindak lanjut dari bahan penyusunan kurikulum dan kepesertaan yang telah dirumuskan oleh bidang program, widyaiswara dan unitunit teknis terkait. Setelah diturunkan Surat Keputusan Sekretaris Jenderal Kementerian Ketenagakerjaan tentang Penunjukan Peserta Diklat Pengantar Kerja. bidang penyelenggara 
mengirimkan surat pemanggilan kepada peserta yang bersangkutan melalui dinas kerja masing-masing. pemanggilan dilakukan dalam rangka konfirmasi kehadiran peserta dan penentuan status bagi peserta cadangan. Bidang penyelenggara mengirimkan surat via pos, surat elektronik, dan melakukan panggilan via telepon.

$$
\text { Kemudian bidang }
$$

penyelenggara mengolah hasil rumusan kurikulum, silabus, dan jadwal untuk diolah menjadi jadwal tentative selama dua bulan diklat berlangsung. Dari jadwal tersebut dijabarkan lagi menjadi jadwal mingguan untuk mengantisipasi perubahan ketika di lapangan. Bidang penyelenggara melakukan penjadwalan terhadap materi dan widyaiswara yang akan mengisi materi. Penyelenggara melakukan pemanggilan terhadap widyaiswara melalui surat permohonan ajar pada hari dua minggu sebelum diklat dilaksanakan.

Pelaksanaan kegiatan pelatihan pengantar kerja dilakukan oleh bidang penyelenggara sebagai penanggungjawab pelaksanaan diklat. Pelaksanaan diklat diawali dari proses perencanaan yang dilakukan oleh bidang program yang kemudian rencana tersebut ditindaklanjuti untuk mencapai tujuan. Sesuai dengan pendapat Shaw mendefinisikan pelaksanaan yaitu, "the purpose of the implementation phase is to implement the training plan that you designed and developed in earlier phase of the systematic approach to training. This is when the learners undertake the activities of learning, produce the various tangible results that can be referenced as means to evaluate learners progress toward achieving the learning objectives, and evaluation occurs not only of the results produced by learners but also the activities of implementation to ensure those activities themselves are high-quality"

Artinya, tujuan dari tahap
implementasi melaksanakan rencana pelatihan yang telah dirancang dan dikembangkan di fase awal untuk pendekatan sistematis pelatihan. Pelaksanaan adalah ketika peserta pelatihan melakukan kegiatan belajar, menghasilkan berbagai hasil nyata yang dapat dirujuk sebagai sarana untuk mengevaluasi kemajuan peserta didik untuk mencapai tujuan pembelajaran, dan evaluasi terjadi tidak hanya dari hasil yang dihasilkan oleh peserta didik tetapi juga kegiatan pelaksanaan untuk memastikan kegiatan tersebut sendiri berkualitas tinggi.

\section{Kesimpulan dan Implikasi}

$$
\text { Proses perencanaan Diklat }
$$

Pengantar Kerja diawali dengan AKD (Analisis Kebutuhan Diklat) pengantar kerja dengan Unit Teknis terkait yaitu Biro Organisasi dan Kepegawaian dan Direktorat Jendral Pembinaan Penempatan Tenaga Kerja dan Perluasan Kesempatan Kerja. Cara mengidentifikasi kebutuhan diklat pengantar kerja adalah dengan melihat kebutuhan masyarakat dari peraturanperaturan yang sudah ada dan melihat kebutuhan setiap daerah yang berbedabeda.

Setelah melakukan tahap analisis kebutuhan, Pusdiklat melakukan tahap perencanaan dari segi program dan penyeleksian peserta. Pusdiklat bersama Direktorat Jendral Pembinaan Penempatan Tenaga Kerja dan Perluasan Kesempatan Kerja, para ahli di bidang ketenagakerjaan dan Widyaiswara mengadakan rapat untuk pembahasan kurikulum yang akan digunakan. Dasar penyusunan materi berada di dalam permenaker yang berkaitan dengan bidang penempatan kemudian dirumuskan kompetensi pengantar kerja dan fungsi di bidang penempatan yang dituangkan ke dalam kurikulum silabus dan mata diklat Dari hasil rapat penentuan tersebut selanjutnya data diberikan kepada bidang 
penyelenggaraan untuk dibuat jadwal tentative selama diklat pengantar kerja berlangsung sehingga akan terlihat gambaran proses acara yang akan dilakukan pada saat pelaksanaan pelatihan.

Setelah diturunkan Surat Keputusan Sekretaris Jenderal Kementerian Ketenagakerjaan tentang Penunjukan Peserta Diklat Pengantar Kerja. bidang penyelenggara mengirimkan surat pemanggilan kepada peserta yang bersangkutan melalui dinas kerja masing-masing. pemanggilan dilakukan dalam rangka konfirmasi kehadiran peserta dan penentuan status bagi peserta cadangan. Kemudian bidang penyelenggara mengolah hasil rumusan kurikulum, silabus, dan jadwal untuk diolah menjadi jadwal tentative selama dua bulan diklat berlangsung.

Kemudian tahap pelaksanaan diklat. Proses pelaksanan diklat. Pelaksanaan diklat pengantar kerja dilakukan selama dua bulan. Kegiatan pembelajaran dimulai dengan BLC (Building Learning Commitment). Dan apel kelas yang dipimpin oleh ketua kelas. Kemudian waktu belajar dari jam delapan pagi hingga sepuluh malam. Untuk melakukan penilaian terhadap aspek pengetahuan peserta dilakukan ujian kompetensi dua minggu sekali dalam bentuk tertulis pada hari Rabu dan Sabtu. Untuk penilaian dari aspek keterampilan yaitu dilakukan PKL (Praktek Kerja Lapangan) yang terdiri dari KKP (Kertas Kerja Perorangan) yang memilki beberapa indikator anatara lain, kemampuan mengidentifikasi masalah, kelengkapan (akurasi dan ketepatan) data, kesungguhan, dan kemampuan menempatkan diri sebagai peserta diklat. Sedangkan dalam aspek sikap berkaitan dengan sikap dan perilaku peserta selama penyelenggaraan diklat berlangsung melalui kegiatan pengamatan sehari-hari di kelas maupun diluar kelas yang terdiri dari aspek disiplin, kerjasama, prakarsa, dan kepemimpinan yang kemudian diolah dalam bentuk penilaian akhir.

Setelah tahap proses pembelajaran baik di luar maupun di dalam kelas tahap selanjutnya adalah seminar akhir diklat. Pada tahap terakhir adalah penentuan kelulusan peserta diklat yang diumumkan pada penutupan. Penilaian bukti kelulusan dimasukan ke dalam sertifikat, yang terdiri dari beberapa kompetensi. Kemudian tindak lanjut setelah peserta mengikuti diklat adalah dengan dilakukan monitoring peserta oleh bidang evaluasi. Pusdiklat memberikan hanya memberikan saransaran ke kepala dinas terkait di dalam surat pengembalian. Pembinaan dan pemberdayaan peserta yg bersangkutan dikembalikan ke unit kerjanya masingmasing.

\section{Saran}

1. Bagi Bidang Program

Saran yang dapat diberikan dalam perencanaan diklat pengantar kerja pada sub-bidang program adalah untuk mempersiapkan lebih awal dan perlu lebih intensif berkomunikasi secara detail dalam mempersiapkan pelatihan dengan pihak unit teknis yang berkaitan.

2. Bagi Bidang Penyelenggaraa

Saran untuk sub-bidang penyelenggara selaku penananggug jawab dalam melakukan pelaksanaan perlu adanya alternative rencana atau konsep pelaksanaan dan langsung disampaikan kepada pihak yang terkait sebelum pelaksanaan pelatihan guna mengantisipasi kesalahan teknis maupun penyesuaian situasi dan kondisi di lapangan sehingga tidak perlu adanya koordinasi ulang. Menurut peraturan panitia yang tertera, panitia penyelenggara harus selalu siap standby ketika peserta atau pengajar memerlukan sesuatu yang 
berhubungan dengan teknis penyelenggaraan.

3. Bagi Widyaiswara

Saran untuk widyaiswara adalah untuk mengecek ulang jadwal mengajar dari jauh-jauh hari dan merencanakan kegiatan mengajar dimana saja yang harus dipenuhi agar mengurangi resiko pembatalan mengajar. Widyaiswara luar biasa bisa menginap di Wisma pada hari sebelum mengajar agar tidak memakan waktu lama di perjalanan dan akhirnya terlambat datang.

4. Bagi Peneliti Lain

Saran untuk peneliti lain adalah agar melakukan penelitian dalam bidang manajemen pelatihan khususnya secara kreatif dan komprehensif agar mendapatkan gambaran proses pelatihan lebih detail dengan menggunakan metode yang baru dan lebih beragam lagi.

\section{Daftar Pustaka}

Basri, Hasan dan Rusdiana. 2015. Manajemen Pendidikan dan Pelatihan. Bandung: Pustaka Setia.

Bernadin, H. John. 2003. Human Resource Management: An Experiental Approach. New York: McGraw-Hill.

Hasibuan, Malayu S.P. 2011. Manajemen (Dasar, Pengertian, dan Masalah), Jakarta: Bumi Aksara

Kambuga, Yusuph. 2013. Introduction to Educational Management and School Administration. Berlin: Lambert Academy Publishing.
Moleong, Lexy J. 2005. Metodologi Penelitian Kualitatif. Bandung: Remaja Rosdakarya.

National Implementation Research Network, Implementation Defined

(http://nirn.fpg.unc.edu/learnimplementation/implementation -defined) diakses pada tanggal 27 November 2016 pukul 15.20 WIB

Noe, Raymond A. 2001. Employee Training and Development. The Ohio State University: McGraw-Hill.

Priansa, Donni Juni . 2014. Perencanaan dan Penegembangan SDM. Bandung: Alfabeta.

Rusdiana dan Ahmad Ghazin. 2014. Asas-asas Manajemen Berwaswasan Global. Bandung: Pustaka Setia.

Shaw, Jack. Implementing Training (http://managementhelp.org/trai ning/systematic/implementingtraining.htm) diakses pada 27 November 2017 pukul 15.50 WIB

Sulchan, Manajemen Pelatihan Kerja di Balai Latihan Kerja Industri Semarang,

(http://lib.unnes.ac.id/16850/1/7 315000066.pdf) diakses pada tanggal 1 November 2016 pukul: $12.51 \mathrm{WIB}$

Tisnawati, Ernie dan Kurniawan Safullah. 2006. Pengantar Manajemen. Jakarta: Prenada Media.

Usman, Husaini. 2012. Manajemen (Teori, Praktik, dan Riset Pendidikan). Yogyakarta: PT. Bumi Aksara. 